\title{
(2) OPEN ACCESS \\ Mortality and respiratory support in X-linked myotubular myopathy: a RECENSUS retrospective analysis
}

\author{
Robert J Graham, ${ }^{1}$ Francesco Muntoni, ${ }^{2}$ Imelda Hughes, ${ }^{3}$ Sabrina W Yum, ${ }^{4}$ \\ Nancy L Kuntz ${ }^{5}$ Michele L Yang, ${ }^{6}$ Barry J Byrne, ${ }^{7}$ Suyash Prasad, ${ }_{1}^{8}$ Rachel Alvarez, ${ }^{9}$ \\ Casie A Genetti, ${ }^{10}$ Tmirah Haselkorn, ${ }^{11}$ Emma S James, ${ }^{8}$ Laurie B LaRusso, ${ }^{12}$ \\ Mojtaba Noursalehi, ${ }^{8}$ Salvador Rico, ${ }^{8}$ Alan H Beggs (i) ${ }^{10}$
}

For numbered affiliations see end of article.

\section{Correspondence to}

Professor Alan H Beggs, Division of Genetics \& Genomics, The Manton Center for Orphan Disease Research, Boston Children's Hospital, Boston, MA 02115, USA;

beggs@enders.tch.harvard. edu and Dr. Robert J Graham, Division of Critical Care Medicine, Dept. of Anesthesiology, Critical Care and Pain Medicine, Boston Children's Hospital, Boston, MA 02115, USA;

robert.graham@childrens. harvard.edu

Received 16 July 2019 Revised 21 August 2019 Accepted 23 August 2019 Published Online First 4 September 2019

\section{SLinked}

- http://dx.doi.org/10.1136/ archdischild-2019-318119

\section{Check for updates}

(C) Author(s) (or their employer(s)) 2020. Re-use permitted under CC BY-NC. No commercial re-use. See rights and permissions. Published by BMJ.

To cite: Graham RJ,

Muntoni F, Hughes I, et al.

Arch Dis Child

2020;105:332-338.

\section{ABSTRACT}

Purpose Individuals with X-linked myotubular myopathy (XLMTM) who survive infancy require extensive supportive care, including ventilator assistance, wheelchairs and feeding tubes. Half die before 18 months of age. We explored respiratory support and associated mortality risk in RECENSUS, particularly among patients $\leq 5$ years old who received respiratory support at birth; this subgroup closely matches patients in the ASPIRO trial of gene therapy for XLMTM.

Design RECENSUS is an international, retrospective study of patients with XLMTM. Descriptive and timeto-event analyses examined survival on the basis of age, respiratory support, tracheostomy use, predicted mutational effects and life-sustaining care.

Results Outcomes for 145 patients were evaluated. Among 126 patients with respiratory support at birth, mortality was $47 \%$ overall and $59 \%$ among those $\leq 5$ years old. Median survival time was shorter for patients $\leq 5$ years old than for those $>5$ years old $(2.2$ years (IQR 0.7-5.6) vs 30.2 years (IQR 19.4-30.2)). The most common cause of death was respiratory failure $(66.7 \%)$. Median survival time was longer for patients with a tracheostomy than for those without (22.8 years (IQR 8.7-30.2) vs 1.8 years (IQR 0.2-not estimable)). The proportion of patients living without a tracheostomy was $50 \%$ at age 6 months and $28 \%$ at age 2 years. Median survival time was longer with provision of life-sustaining care than without (19.4 years (IQR 3.1-not estimable) vs 0.2 years (IQR $0.1-2.1)$ ).

Conclusions High mortality, principally due to respiratory failure, among patients with XLMTM $\leq 5$ years old despite respiratory support underscores the need for early diagnosis, informed decision-making and diseasemodifying therapies.

Trial registration number NCT02231697

\section{INTRODUCTION}

$\mathrm{X}$-linked myotubular myopathy (XLMTM) is a rare congenital myopathy resulting from pathogenic variants in the MTM1 gene, which encodes the protein myotubularin, a lipid phosphatase that is required for normal development, maturation and maintenance of skeletal muscle cells. ${ }^{12}$ Affecting an estimated 1 in 40000-50000 live male births, ${ }^{34}$ XLMTM often manifests as profound congenital muscle weakness ${ }^{1}$; infants typically present with

\section{What is already known on this topic?}

X-linked myotubular myopathy (XLMTM) is associated with substantial disease burden, including respiratory support at birth $(90 \%$ of patients), 24-hour ventilator dependence (48\%) and tracheostomy $(60 \%)$.

- Patients with XLMTM have high rates of hospitalisation and surgical intervention in their first year of life.

- Nearly half of children with XLMTM die of respiratory failure or related complications in their first 18 months of life.

\section{What this study adds?}

- The most common cause of death among patients with XLMTM is respiratory failure, despite nearly universal use of respiratory support from birth.

- High mortality and rapid progression to death among patients aged 5 years and younger underscore the need for early diagnosis and a disease-modifying therapy.

- Patients who survive face considerable lifelong clinical demands, including tracheostomy and ventilator dependence.

severe hypotonia, weakness and respiratory distress. ${ }^{56}$ Nearly half die by 18 months of age from respiratory failure or related complications, such as pneumonia, respiratory tract infections or ventilator-related accidents. ${ }^{6-8}$ Most who survive infancy require mechanical ventilation and supplementary feeding, rely on wheelchairs for mobility, undergo multiple surgeries in their first year of life and die in early childhood. ${ }^{9}{ }^{10}$ Those who survive face substantial physical, emotional and financial demands related to their reliance on life-sustaining ventilatory and other forms of support. ${ }^{11-13}$

In the absence of disease-modifying treatment for XLMTM, medical management is limited to multidisciplinary supportive care to maximise functional abilities and minimise complications. ${ }^{13}$ As an X-linked recessive monogenic disease, therapy designed to replace the defective MTM1 gene with a 
normal copy could potentially correct the underlying pathology that results from defective myotubularin expression. ${ }^{14}$ The phase I/II ASPIRO trial (NCT03199469) is a first-in-human study evaluating the safety, tolerability and preliminary efficacy of a gene therapy product ( $r A A V 8$-Des-hMTM1) to restore myotubularin expression and ameliorate disease manifestations. Given the rarity of this disorder, patient outcomes in ASPIRO and other clinical trials will need to be evaluated in the context of the natural history of XLMTM.

RECENSUS (Audentes Therapeutics, San Francisco, California) is a large, retrospective, multicentre, medical chart review whose aim is to characterise the XLMTM disease manifestations and medical management. Initial analyses demonstrated substantial disease burden, including respiratory support at birth for $90 \%$ of patients, 24 -hour ventilator dependence for $48 \%$, tracheostomy for $60 \%$, and high rates of hospitalisation and surgical intervention in the first year of life. ${ }^{10}$ The current analysis explores respiratory support in relation to associated risk of mortality among an expanded cohort of patients who received respiratory support at birth, and the subgroup of patients that most closely matches patients in the INCEPTUS longitudinal, run-in study (NCT02704273) and ASPIRO clinical trial (ie, children $\leq 5$ years receiving respiratory support at birth).

\section{METHODS}

\section{Study design}

RECENSUS is an ongoing, international, multicentre, retrospective medical record review of males diagnosed with XLMTM based either on genetic testing of their MTM1 genes, or clinical affection status of individuals with a genetically confirmed family history of XLMTM and muscle biopsy. Methods of patient ascertainment and data collection were reported previously. ${ }^{10}$ This analysis includes data from primary medical records collected from eight international sites between 10 September 2014 and 15 August 2018. Some cases were reported previously in the literature..$^{5-7} 91516$ Genotype, mortality and respiratory support data from RECENSUS were assessed in the current analysis.

\section{Genetic analysis and classification}

MTM1 mutation status was derived from clinical testing and review of the medical record or from prior published research studies. $^{3-5}$ 10 $^{17-19}$ Variants were listed relative to GenBank reference sequence NM_000252.2, and predicted effects on protein structure were numbered according to NP_000243.1. Each allele was classified as described below to predict which were likely null mutations leading to little or no stable protein versus those where muscle might express stable intact or internally deleted proteins, possibly with residual activity. Loss of function (LOF) alleles included all predicted genetic null mutations. Predicted hypomorphs were grouped into two classes: partial loss of function (PLOF) variants (defined as inframe single exon duplications, three base pair inframe deletions, inframe insertions, small inframe indels and missense variants) and inframe exonic deletions (IFED), predicted to encode stable but internally deleted proteins that might be missing entire functional domains and antigenic epitopes.

\section{Statistical analysis}

Descriptive analyses were performed for the total cohort, the subgroup of patients with documented respiratory support at birth and the subgroup of patients currently $\leq 5$ years with documented respiratory support at birth. Patient age was determined using the
Table 1 Patient and disease characteristics

\begin{tabular}{|c|c|c|}
\hline & $\begin{array}{l}\text { Age } \leq 5 \text { years } \\
\text { and respiratory } \\
\text { support at birth } \\
(\mathrm{n}=82)\end{array}$ & $\begin{array}{l}\text { All patients } \\
(\mathrm{N}=145)\end{array}$ \\
\hline $\begin{array}{l}\text { Age at XLMTM genetic diagnosis (months), } \\
\mathrm{n}\end{array}$ & 80 & 142 \\
\hline Mean (SD) & $6.5(7.5)$ & $33.0(61.3)$ \\
\hline Quartiles (25th, median, 75th) & $2,4,7$ & $3,6,27$ \\
\hline Decreased fetal movement, $\mathrm{n} / \mathrm{N}(\%)$ & $44 / 82(53.7)$ & $75 / 142(52.8)$ \\
\hline $\begin{array}{l}\text { Weeks when decreased fetal movement } \\
\text { noted, } \mathrm{n}\end{array}$ & 10 & 17 \\
\hline Mean (SD) & $29.7(4.6)$ & $28.6(4.6)$ \\
\hline Quartiles (25th, median, 75th) & $28,31,34$ & $25,29,32$ \\
\hline Polyhydramnios, n/N (\%) & $44 / 82(53.7)$ & $70 / 142(49.3)$ \\
\hline Weeks when polyhydramnios noted, $\mathrm{n}$ & 24 & 31 \\
\hline Mean (SD) & $30.9(5.8)$ & $30.8(5.4)$ \\
\hline Quartiles (25th, median, 75th) & $28,32,36$ & $28,31,36$ \\
\hline Premature (<36 weeks) delivery, $\uparrow \mathrm{n} / \mathrm{N}(\%)$ & $28 / 82(34.1)$ & $43 / 142(30.3)$ \\
\hline Weeks at premature delivery, $\mathrm{n}$ & 28 & 43 \\
\hline Mean (SD) & $32.4(2.3)$ & $32.6(2.2)$ \\
\hline Quartiles (25th, median, 75th) & $31,33,34$ & $31,33,34$ \\
\hline Apgar score 1 min after birth, $\mathrm{n}(\%)$ & 65 & 102 \\
\hline$\geq 7$ (normal) & $2(3.1)$ & $8(7.8)$ \\
\hline 4-6 (intermediate) & $13(20.0)$ & $23(22.5)$ \\
\hline $0-3$ (low) & $50(76.9)$ & $71(69.6)$ \\
\hline Apgar score 5 min after birth, $\mathrm{n}(\%)$ & 64 & 100 \\
\hline$\geq 7$ (normal) & $11(17.2)$ & $24(24.0)$ \\
\hline 4-6 (intermediate) & $34(53.1)$ & $51(51.0)$ \\
\hline $0-3$ (low) & $19(29.7)$ & $25(25.0)$ \\
\hline $\begin{array}{l}\text { Type of respiratory support required first } \\
24 \text { hours after birth, } n(\%)\end{array}$ & 82 & 133 \\
\hline IPPV/SIMV/pressure support & $44(53.7)$ & $71(53.4)$ \\
\hline CPAP/BiPAP & $24(29.3)$ & $31(23.3)$ \\
\hline Supplemental oxygen & $3(3.7)$ & $7(5.3)$ \\
\hline Not documented & $11(13.4)$ & $24(18.0)$ \\
\hline \multicolumn{3}{|c|}{$\begin{array}{l}\text { Column header counts are the number of patients who have non-missing mortality } \\
\text { data. For each characteristic, n refers to the number of patients with non-missing } \\
\text { data for that characteristic. } \\
\text { *Age at diagnosis was calculated using the date of genetic confirmation. } \\
\text { tPremature delivery was defined as delivery before } 36 \text { weeks. } \\
\text { BiPAP, bilevel positive airway pressure; CPAP, continuous positive airway pressure; } \\
\text { IPPV, intermittent positive pressure ventilation; SIMV, synchronised intermittent } \\
\text { mechanical ventilation; XLMTM, X-linked myotubular myopathy. }\end{array}$} \\
\hline
\end{tabular}

latest date available in the database. For patients currently alive, this was the last contact date or last known alive date. For deceased patients, this was the date of death. In Kaplan-Meier time-to-event analyses, patients without an event (ie, death or tracheostomy) were censored at their last known alive date (ie, latest date available in the database). Missing date of death was imputed as 1 day after their last known alive date; missing tracheostomy placement date was imputed based on the first hospitalisation record indicating presence of tracheostomy. Two patients were excluded from the tracheostomy analysis because records provided no indication of when the tracheostomy was placed.

\section{RESULTS}

\section{Patient characteristics}

A total of 145 boys with genetically confirmed XLMTM in the RECENSUS database who had available mortality data were included (table 1). The mean age at diagnosis was 33.0 months 
in the total cohort $(\mathrm{N}=145)$ and 6.5 months among patients $\leq 5$ years who received respiratory support at birth $(n=82)$. In both cohorts, approximately half of patients had a history of decreased fetal movement and polyhydramnios, and a third were born prematurely. More than $90 \%$ of patients in both cohorts had low (0-3) or intermediate (4-6) Apgar scores 1 min after birth, and more than $75 \%$ remained low or intermediate 5 min after birth. In the first 24 hours after birth, most patients in both cohorts received some form of respiratory support: 53\%-54\% invasive (ie, transtracheal intubation) respiratory support, 23\%-29\% non-invasive positive pressure respiratory support and $4 \%-5 \%$ supplemental oxygen.

Genetic variants and predicted impacts on protein expression Genetic characteristics for the overall cohort have been reported previously, ${ }^{10}$ and mutations in the 33 additional affected individuals largely mirror the broader group. All 145 boys, or a similarly affected first-degree relative, had an MTM1 mutation classified as either pathogenic or likely pathogenic according to the American College of Medical Genetics criteria for variant interpretation. ${ }^{20}$ The cohort includes 100 unique variants throughout the gene in a distribution similar to that previously reported. ${ }^{10}{ }^{15}$ Functional classification of MTM1 variants includes 63 patients (43.4\%) with predicted LOF variants (including 34 frameshift indels, 21 stopgain variants, 3 splice site variants predicted to cause a frameshift, 3 exon 1 deletions, 1 start-loss variant and 1 complex gene rearrangement); 65 patients $(44.8 \%)$ classified as PLOF (including 55 missense changes and 10 inframe indels); 16 IFED patients $(11 \%)$ with larger inframe deletions $(n=3)$ or splice site variants $(n=13)$ predicted to result in loss of a single exon inframe; and 1 patient with an exon 15 frameshift mutation, p.His598Metfs*23, predicted to encode a near full-length protein and previously reported to have a mild phenotype. ${ }^{5}$

\section{Mortality}

Of the 145 boys included, 7 did not require respiratory support at birth and 12 had no documentation regarding respiratory support at birth and were therefore excluded from mortality analyses. The remaining 126 patients (87.0\%) received respiratory support at birth, of whom 82 patients $(56.6 \%)$ were $\leq 5$ years. Mortality was $47 \%$ overall (estimated median follow-up: 7.85 years) and $59 \%$ among those $\leq 5$ years (estimated median follow-up: 3.11 years) (table 2). Among 39 patients with respiratory support at birth and documented cause of death, the most common cause of death was respiratory failure $(66.7 \%)$, followed by cardiorespiratory arrest (18\%) and liver bleeds associated with hepatic peliosis (10\%). A similar pattern for cause of death was observed among 30 patients $\leq 5$ years who received respiratory support at birth and had documented cause of death (table 2). Among all patients who received respiratory support at birth, the median time to death in those $\leq 5$ years was 2.2 years (IQR $0.7-5.6$ ) vs 30.2 years (IQR 19.4-30.2) in those $>5$ years (figure 1A). Among the seven patients who did not require respiratory support at birth (one $\leq 5$ years and six $>5$ years), one patient $>5$ years died (cause of death not documented).

Survival among all 145 patients was also assessed as a function of predicted mutational effects on myotubularin protein (figure 1B). Patients with predicted MTM1 null mutations, classified as LOF, had the worst prognosis, with a median time to death of 6.2 years. In contrast, PLOF patients, composed largely of patients with missense mutations and a few inframe duplications, had markedly longer median survival of 30.2
Table 2 Mortality and withholding of life-sustaining therapy in patients who required respiratory support at birth

\begin{tabular}{lll}
\hline & $\begin{array}{l}\text { Age } \leq 5 \text { years } \\
\text { and respiratory } \\
\text { support at birth } \\
(\mathbf{n}=82)\end{array}$ & $\begin{array}{l}\text { All patients } \\
\text { with respiratory } \\
\text { support at birth } \\
(\mathbf{n}=126)\end{array}$ \\
\hline Deaths, $\mathrm{n}(\%)$ & $48(58.5)$ & $59(46.8)$ \\
\hline Country, $\mathrm{n}(\%)$ & & \\
\hline USA & $29(60.4)$ & $39(66.1)$ \\
\hline Non-USA & $19(39.6)$ & $20(33.9)$ \\
\hline Country/region, $\mathrm{n}(\%)$ & & \\
\hline USA & $29(60.4)$ & $39(66.1)$ \\
\hline Europe & $11(22.9)$ & $12(20.3)$ \\
\hline Canada & $5(10.4)$ & $5(8.5)$ \\
\hline South America & $2(4.2)$ & $2(3.4)$ \\
\hline Australia & $1(2.1)$ & $1(1.7)$ \\
\hline Deaths with documented cause, $\mathrm{n}$ (\%) & $30(62.5)$ & $39(66.1)$ \\
\hline Respiratory failure & $24(80.0)$ & $26(66.7)$ \\
\hline Cardiorespiratory arrest & $4(13.3)$ & $7(17.9)$ \\
\hline Hepatic peliosis & $2(6.7)$ & $4(10.3)$ \\
\hline Other & $3(10.0)$ & $5(12.8)$ \\
\hline 'Died suddenly in his sleep', no autopsy & 0 & $1(20.0)$ \\
\hline Intra-abdominal haemorrhage (hepatic & 0 & $1(20.0)$ \\
\hline capsular rupture) & & $20(33.9)$ \\
\hline Deaths without documented cause, $\mathrm{n}(\%)$ & $18(37.5)$ & $27 / 59(45.8)$ \\
\hline Life-sustaining therapy withheld among \\
deceased patients, $\mathrm{n} / \mathrm{N}$ (\%) & $24 / 48(50.0)$ & $11 / 27(40.7)$ \\
\hline USA & $10 / 24(41.7)$ & $16 / 27(59.3)$ \\
\hline Non-USA & $14 / 24(58.3)$ & \\
\hline Coly & & \\
\hline
\end{tabular}

Column header counts are the number of patients who have non-missing mortality data. For each characteristic, $n$ refers to the number of patients with non-missing data for that characteristic.

years. IFED patients, defined as individuals with inframe deletions of one or more exons, had survival times consistent with PLOF patients, supporting the notion that internal loss of myotubularin sequences is compatible with partial protein function in at least some cases.

\section{Respiratory support}

Of patients with respiratory support at birth, 60\% overall and $49 \%$ of those $\leq 5$ years had a tracheostomy (table 3 ). The median time to placement was 3 months of age. The median time to death for patients with a tracheostomy was 22.8 years (IQR 8.7-30.2) compared with 1.8 years (IQR 0.2-not estimable) for patients without a tracheostomy (figure 1C). Tracheostomy-free survival decreased rapidly over time. By 6 months of age, $50 \%$ of patients who remained alive were living without a tracheostomy, declining to $28 \%$ at 2 years of age and $18 \%$ at 4 years of age. More than half of patients were ventilator-dependent $\geq 16$ hours per day at some point (table 3); almost half of those patients (47.2\%) died, while the other half (52.8\%) remained alive with invasive ventilation and no decrease in their ventilation requirements. Both tracheostomy (67\% vs 44\%) and ventilator dependence $\geq 16$ hours per day $(63 \%$ vs $42 \%$ ) were more prevalent in the USA than outside the USA (Europe, Canada, South America and Australia) (table 3).

\section{Utilisation or limitation of life-sustaining support}

Life-sustaining support in the form of mechanical ventilator support was withheld or withdrawn in 27 of 63 patients (43\%) with reported data. The median time to death for patients receiving life-sustaining care was 19.4 years (IQR 3.1-not 
A

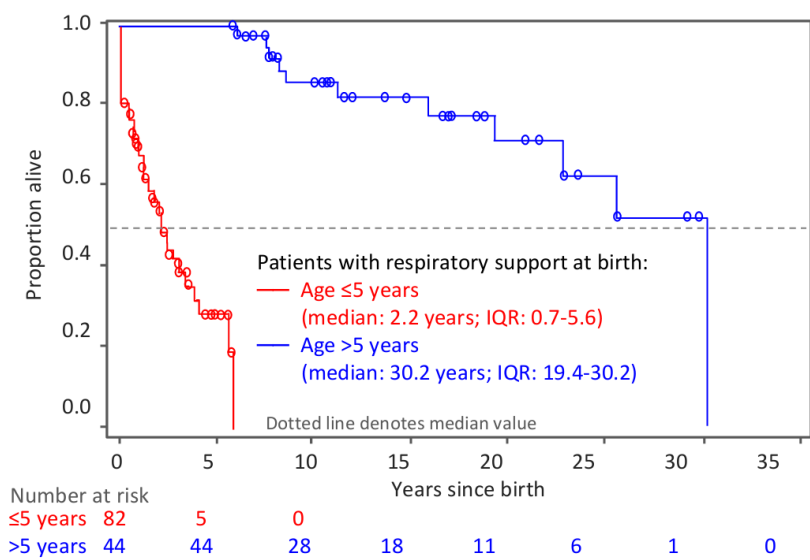

B

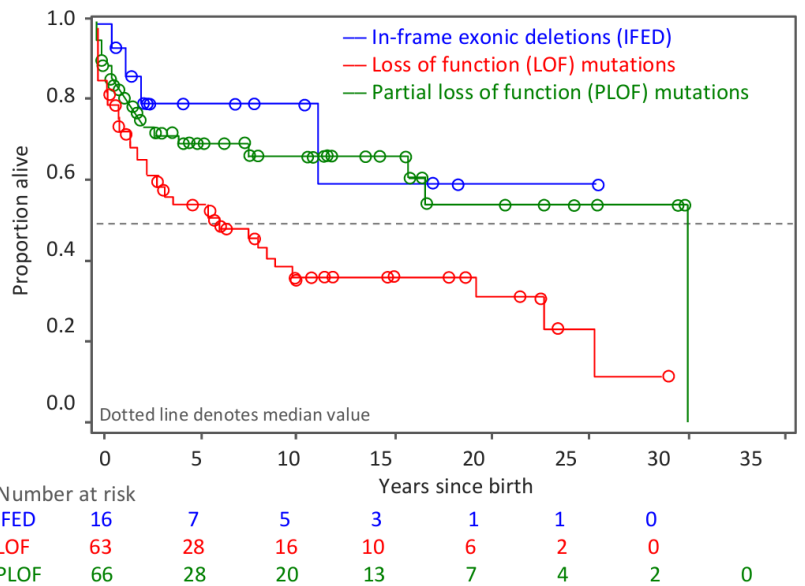

C

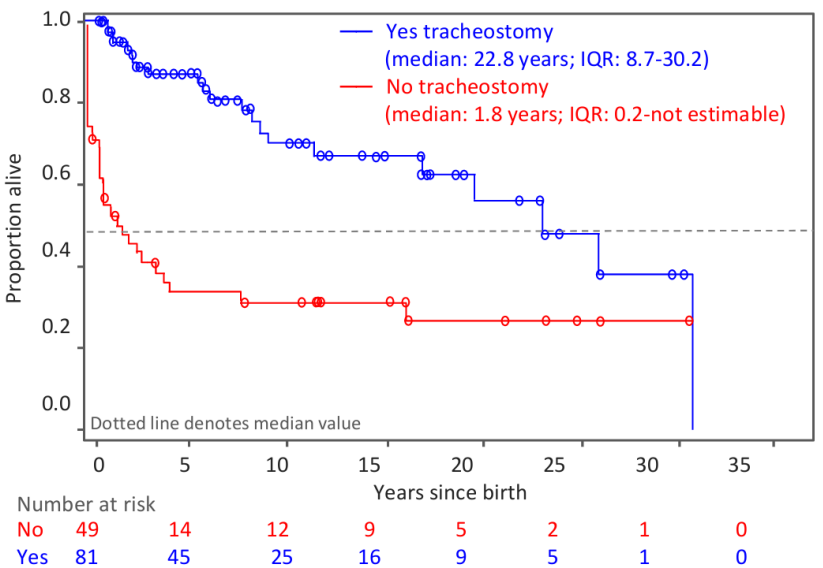

IQR: interquartile range

Figure 1 Kaplan-Meier analyses. (A) Time to death by age ( $\leq 5$ vs $>5$ years) for patients who required respiratory support at birth. (B) Time to death by mutation class. (C) Time to death by tracheostomy status.

estimable) compared with 0.2 years (IQR 0.1-2.1) when lifesustaining support was withheld (figure 2A). Of 18 patients who died in the first 6 months of life, 15 did not have a tracheostomy and 3 had no documentation regarding tracheostomy placement. Among 16 patients with documentation of their age when lifesustaining support was withheld or withdrawn, 10 patients were less than 2.5 months of age and 6 patients were between 8.5 months and 30 years of age (figure $2 \mathrm{~B}$ ).

\section{DISCUSSION}

\section{Survival and respiratory support}

Findings from the comprehensive retrospective RECENSUS study demonstrate early disease presentation, profound respiratory insufficiency with need for respiratory interventions and high mortality, which are consistent with previous smaller studies. ${ }^{6710}$ The high proportion of patients on ventilator support $\geq 16$ hours per day (ie, permanent ventilation) further underscores the morbidity of this severe neuromuscular disease. Children requiring this level of support are unlikely to have intrinsic capacity to wean and would die without such interventions ${ }^{21}$; in addition, they and their families face substantial physical, emotional and financial demands associated with their need for mechanical ventilation. ${ }^{11-13}$ One cannot discount the possibility that some patients felt likely to do better by their managing care teams might have been more likely to be offered intervention. Nevertheless, rapid progression to death among children $\leq 5$ years and poor tracheostomy-free survival rates at 2 years of age in RECENSUS support the need for early disease recognition through consideration of XLMTM in the evaluation of infantile/congenital hypotonia. As expected, most deceased patients died of respiratory failure. However, it is likely that respiratory failure also contributed to deaths attributed to cardiac failure, given that prolonged respiratory arrest results in a terminal cardiac event, and these patients had no history or documented evidence of underlying cardiomyopathy to suggest mortality due to primary cardiac events. Of note, the four deaths attributed to complications of hepatic peliosis (plus a hepatic capsular rupture due to probable peliosis) in this population is higher than reported previously in the literature, ${ }^{79}$ which raises important issues of standard-of-care surveillance in this population.

\section{Genetic contributions to disease severity}

Genetic characteristics in the RECENSUS cohort are consistent with previous reports, ${ }^{5-79151622}$ with a wide distribution of types and locations of MTM1 mutations. Sixty-three patients (43.4\%) were classified as LOF with predicted null mutations expected to produce little or no functional or stable myotubularin. As a group, these patients experienced earlier mortality than the PLOF and IFED groups, whose mutations were predicted to allow production of full-length or internally deleted proteins. Potential differences in outcomes of myotubularin replacement therapy will need to be assessed.

\section{Life-sustaining ventilator support}

Physicians and parents are cognisant of the perceived futility of medical management and reduced quality of life projected for children with XLMTM. While respiratory support reduces mortality, many survivors become fully reliant on invasive ventilation. Opinion, practice and family decision-making around respiratory support in neuromuscular disorders, such as spinal muscular atrophy type 1 and Duchenne muscular dystrophy, have changed over decades, and there remains substantial variation in physician practice for recommending life-sustaining care..$^{23-26}$ Concern among medical providers about poor quality of life is often the reason for not proceeding with long-term mechanical ventilation. ${ }^{23}$ In North America, however, aggressive non-invasive measures ${ }^{27-29}$ and indications for tracheostomy in infants and children with neuromuscular diseases have been expanding over recent decades. ${ }^{17}{ }^{19}{ }^{30-32}$ This may be reflected in the higher proportion of tracheostomised RECENSUS patients from the USA compared with other regions. Although patient numbers are small, results suggest that decisions to not proceed with life-sustaining care occur predominantly within the first 2 months of life. The decision to withdraw life-sustaining ventilator support later in life is often 
Table 3 Respiratory and ventilator support among patients who required respiratory support at birth

\begin{tabular}{|c|c|c|c|c|}
\hline & \multicolumn{4}{|c|}{ Patients with respiratory support at birth } \\
\hline & Age $\leq 5$ years $(n=82)$ & All patients $(\mathrm{N}=126)$ & US patients $(n=90)$ & Non-US* patients $(n=36$ \\
\hline Tracheostomy, n (\%) & $40(48.8)$ & $76(60.3)$ & $60(66.7)$ & $16(44.4)$ \\
\hline Age at tracheostomy (months), $\mathrm{n}$ & 38 & & 60 & 14 \\
\hline Mean (SD) & $4.7(4.3)$ & $9.5(19.9)$ & $10.1(21.9)$ & $7.3(6.0)$ \\
\hline Quartiles (25th, median, 75th) & $2,4,6$ & $2,3,8$ & $2,3,7$ & $3,6,9$ \\
\hline \multicolumn{5}{|c|}{ Ventilator-dependent $\geq 16$ hours per day, $n$ (\%) } \\
\hline Yes & $47(57.3)$ & $72(57.1)$ & $57(63.3)$ & $15(41.7)$ \\
\hline No & $18(22.0)$ & $30(23.8)$ & $19(21.1)$ & $11(30.6)$ \\
\hline Not documented & $17(20.7)$ & $24(19.0)$ & $14(15.6)$ & $10(27.8)$ \\
\hline
\end{tabular}

Column header counts are the number of patients who have non-missing mortality data. For each characteristic, $\mathrm{n}$ refers to the number of patients with non-missing data for that characteristic.

*Europe, Canada, South America and Australia.

in response to an acute event or significant cumulative morbidities, such as severe hypoxic-ischaemic insults. Practice and ethical considerations of long-term home ventilation in neuromuscular diseases are evolving and will likely continue with the advent of treatments that reduce morbidity and improve quality of life and survival for these patients. ${ }^{33} 34$

\section{Limitations}

Retrospective chart reviews are valuable tools to better understand rare diseases when natural history information is sparse. RECENSUS has helped characterise disease burden and medical management of XLMTM, ${ }^{10}$ as well as the extensive ventilator dependence, high mortality and premature death associated with this disease. Studies of diseases with high mortality may be biased towards inclusion of surviving patients (ie, ascertainment bias) due to increased likelihood of consent from living patients' parents

A
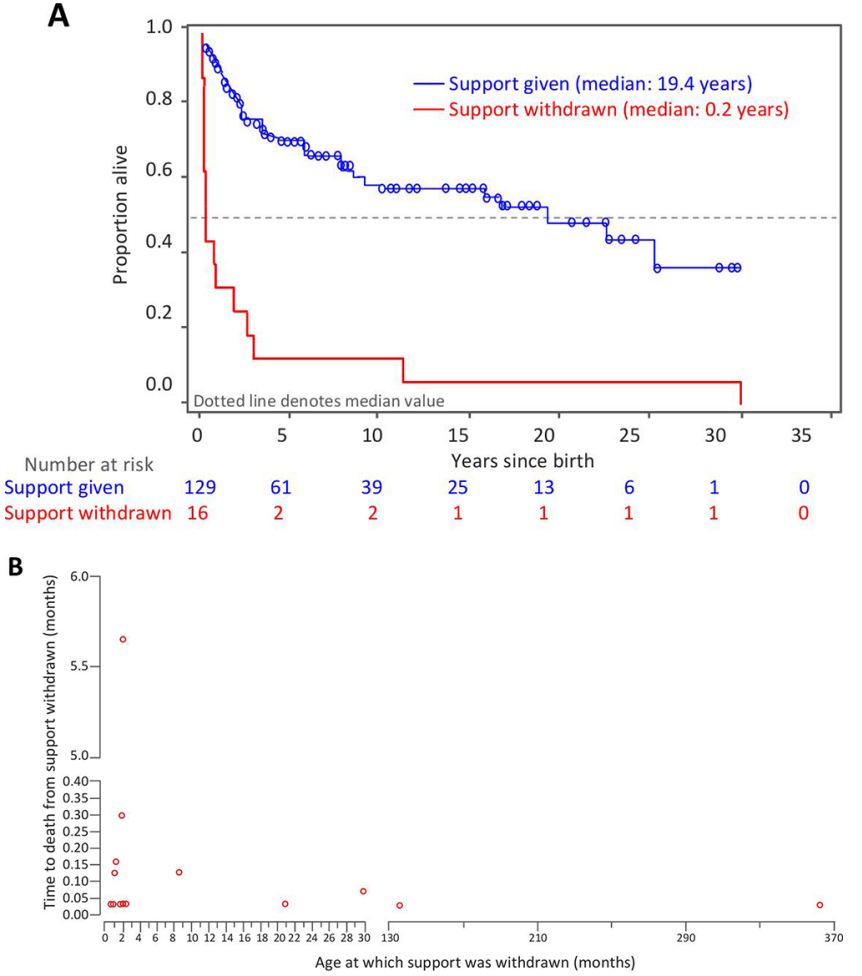

Figure 2 Withdrawal of life-sustaining support. (A) Kaplan-Meier analysis of time to death by whether life-sustaining support was withdrawn or maintained. (B) Age at which life-sustaining support was withdrawn $(n=16)$. and difficulty obtaining ethics committee approval for deceased patients. Survival statistics in RECENSUS must be interpreted with caution due to decreases in patients at risk after childhood. Furthermore, retrospective chart reviews are subject to variable completeness and quality of data compared with the stringent data collection protocols of prospective studies, such as clinical trials.

\section{Investigational gene therapy for XLMTM}

Several therapeutic strategies for XLMTM are in development, including gene therapy, ${ }^{14336}$ myotubularin protein replacement, ${ }^{37}$ downregulation of dynamin 2 expression ${ }^{38} 39$ and inhibition of PIK3C2B22 activity. ${ }^{40}$ At this time, only the gene therapy $r A A V 8$ Des-hMTM1 (AT132, Audentes Therapeutics) has entered human trials. Early results for the first nine treated patients in the ASPIRO clinical trial of this gene therapy showed significant measurable improvements in neuromuscular function (achievement of motor milestones; increased limb and trunk strength; and improved velocity, coordination and accuracy of movement) and respiratory function (marked decrease in ventilator dependence and increased respiratory pressures) in the first 24 weeks on therapy (data as of 26 September 2018). ${ }^{41}$ Four treated patients were weaned off ventilator support completely, which was not achieved among any members of the RECENSUS cohort or in recent prospective studies in patients with XLMTM. ${ }^{92}$ RECENSUS data will be integral to ongoing assessment of the impact of disease-modifying therapies on XLMTM disease course.

\section{CONCLUSIONS}

Data from RECENSUS underscore the high mortality in young children with XLMTM, principally due to respiratory causes. In patients who survive, there remains considerable clinical burden, including frequent tracheostomy and ventilator dependence, which impact on patient function and quality of life for patients, families and caregivers. Shared decision-making between families of children with XLMTM and their care teams has supported a range of palliative and supportive care options. Increasing access to advanced homecare technologies has provided families with more options, but considerations of quality of life, care demands, and progression of XLMTM remain factors that families must account for in choosing between different management options. The prospect of gene-targeted, or replacement, therapies becoming available in the foreseeable future further complicates families' decision-making, but at the present time choices between invasive or non-invasive ventilation and degree of support should be considered ethically equivalent. Regardless, our findings illustrate unmet medical needs for patients with XLMTM and highlight the value of early diagnosis for disease management and the potential for 
early provision of disease-modifying therapies, which are currently investigational.

\section{Author affiliations}

'Department of Anesthesiology, Critical Care and Pain Medicine, Division of Critical Care Medicine, Boston Children's Hospital, Harvard Medical School, Boston, Massachusetts, USA

${ }^{2}$ The Dubowitz Neuromuscular Centre, UCL Great Ormond Street Institute of Child Health and NIHR Great Ormond Street Hospital Biomedical Research Centre, London, UK

${ }^{3}$ Royal Manchester Children's Hospital, Manchester, UK

${ }^{4}$ Children's Hospital of Philadelphia, Perelman School of Medicine at the University of Pennsylvania, Philadelphia, Pennsylvania, USA

${ }^{5}$ Ann and Robert H Lurie Children's Hospital of Chicago, Chicago, Illinois, USA

${ }^{6}$ Children's Hospital Colorado, Aurora, Colorado, USA

${ }^{7}$ Children's Research Institute, University of Florida, Gainesville, Florida, USA

${ }^{8}$ Audentes Therapeutics, San Francisco, California, USA

${ }^{9}$ Cure CMD, Torrance, California, USA

${ }^{10}$ Division of Genetics and Genomics, The Manton Center for Orphan Disease

Research, Boston Children's Hospital, Harvard Medical School, Boston,

Massachusetts, USA

${ }^{11}$ EpiMetrix, Los Altos, California, USA

${ }^{12}$ Chestnut Medical Communications, Walpole, Massachusetts, USA

Acknowledgements We would like to thank the patients and families with XLMTM who allowed their data to be collected for the RECENSUS study. We thank Sabine de Chastonay, PhD, of Cure CMD for collection of patient records on behalf of Cure CMD, and Alison Frase for collection of patient information through the Frase Foundation Family Registry. We are also grateful for support from the XLMTM patient advocacy community: The Joshua Frase Foundation; MTM-CNM Family Connection; the Myotubular Trust; Where There's a Will There's A Cure Foundation for Myotubular Myopathy; and ZNM - Zusammen Stark! Thanks also to the clinical operations team at Audentes Therapeutics and IND 2 Results for assistance with data acquisition.

Contributors SP conceptualised the study. AHB, CAG, RA, NLK, MLY and SWY collected data and contributed to the interpretation of data. MN conducted the statistical analyses. AHB, LBL, RJG, ESJ, SR and TH wrote the manuscript.

Funding The RECENSUS study was funded by Audentes Therapeutics. Support for subject ascertainment, enrolment and data acquisition was provided by the National Institutes of Health (grant R01 AR044345) and Muscular Dystrophy Association (USA) (grant MDA602235). Data aggregation was also achieved through neuromuscular clinics supported by the Muscular Dystrophy Association (USA).

Competing interests RJG, IH, MLY, NLK and SWY report no conflicts of interest with respect to this study. RJG is an unpaid member of Audentes Therapeutics Board of Scientific and Clinical Advisors. RA is a volunteer for Cure CMD and has no financial interest in Audentes or related to this study. LBL received financial compensation for medical writing, and TH is a consultant to Audentes Therapeutics. ESJ, MN, SR and SP are employees and shareholders of Audentes Therapeutics. AHB is a member of the Audentes Therapeutics Board of Scientific and Clinical Advisors and has received support from a sponsored research agreement with Audentes Therapeutics to cover running costs for this study.

Patient consent for publication Not required.

Ethics approval The study protocol was reviewed and approved by the Western Institutional Review Board (IRB) (Pr No 20141715) and the local IRBs at participating institutions. Informed consent was obtained from the parent(s) or legal guardian(s) of each patient and/or assent by the patient (when applicable) before initiating medical record review.

Provenance and peer review Not commissioned; externally peer reviewed.

Data availability statement Data are available upon reasonable request.

Open access This is an open access article distributed in accordance with the Creative Commons Attribution Non Commercial (CC BY-NC 4.0) license, which permits others to distribute, remix, adapt, build upon this work non-commercially, and license their derivative works on different terms, provided the original work is properly cited, appropriate credit is given, any changes made indicated, and the use is non-commercial. See: http://creativecommons.org/licenses/by-nc/4.0/.

\section{ORCID iD}

Alan H Beggs http://orcid.org/0000-0001-8818-0568

\section{REFERENCES}

1 Dowling JJ, Lawlor MW, Das S. X-Linked Myotubular Myopathy. In: Adam MP, Ardinger HH, Pagon RA, eds. GeneReviews((R))1993-2019. Seattle (WA), 2002.

2 Hnia K, Vaccari I, Bolino A, et al. Myotubularin phosphoinositide phosphatases: cellular functions and disease pathophysiology. Trends Mol Med 2012;18:317-27.
3 Jungbluth H, Wallgren-Pettersson C, Laporte J. Centronuclear (myotubular) myopathy. Orphanet J Rare Dis 2008;3:26.

4 Vandersmissen I, Biancalana V, Servais L, et al. An integrated modelling methodology for estimating the prevalence of centronuclear myopathy. Neuromuscul Disord 2018;28:766-77

5 Herman GE, Kopacz K, Zhao W, et al. Characterization of mutations in fifty North American patients with X-linked myotubular myopathy. Hum Mutat 2002;19:114-21.

6 McEntagart M, Parsons G, Buj-Bello A, et al. Genotype-Phenotype correlations in X-linked myotubular myopathy. Neuromuscul Disord 2002;12:939-46.

7 Herman GE, Finegold M, Zhao W, et al. Medical complications in long-term survivors with X-linked myotubular myopathy. J Pediatr 1999;134:206-14.

8 Wallgren-Pettersson C, Clarke A, Samson F, et al. The myotubular myopathies: differential diagnosis of the $\mathrm{X}$ linked recessive, autosomal dominant, and autosoma recessive forms and present state of DNA studies. J Med Genet 1995;32:673-9.

9 Amburgey K, Tsuchiya E, de Chastonay S, et al. A natural history study of X-linked myotubular myopathy. Neurology 2017;89:1355-64.

10 Beggs $\mathrm{AH}$, Byrne BJ, De Chastonay S, et al. A multicenter, retrospective medical record review of $X$-linked myotubular myopathy: the recensus study. Muscle Nerve 2018;57:550-60.

11 González R, Bustinza A, Fernandez SN, et al. Quality of life in home-ventilated children and their families. Eur J Pediatr 2017:176:1307-17.

12 Graham RJ, Rodday AM, Parsons SK. Family-centered assessment and function for children with chronic mechanical respiratory support. J Pediatr Health Care 2014:28:295-304.

13 Graham RJ, Rodday AM, Weidner RA, et al. The impact on family of pediatric chronic respiratory failure in the home. J Pediatr 2016;175:40-6.

14 Childers MK, Joubert R, Poulard K, et al. Gene therapy prolongs survival and restores function in murine and canine models of myotubular myopathy. Sci Trans/ Med 2014;6:220ra210.

15 Oliveira J, Oliveira ME, Kress W, et al. Expanding the MTM1 mutational spectrum: novel variants including the first multi-exonic duplication and development of a locusspecific database. Eur J Hum Genet 2013;21:540-9.

16 Pierson CR, Agrawal PB, Blasko J, et al. Myofiber size correlates with MTM1 mutation type and outcome in X-linked myotubular myopathy. Neuromuscul Disord 2007:17:562-8.

17 Carron JD, Derkay CS, Strope GL, et al. Pediatric tracheotomies: changing indications and outcomes. Laryngoscope 2000;110:1099-104.

18 Laporte J, Blondeau F, Buj-Bello A, et al. The myotubularin family: from genetic disease to phosphoinositide metabolism. Trends Genet 2001;17:221-8.

19 Line WS, Hawkins DB, Kahlstrom EJ, et al. Tracheotomy in infants and young children: the changing perspective 1970-1985. Laryngoscope 1986;96:510-5.

20 Richards S, Aziz N, Bale S, et al. Standards and guidelines for the interpretation of sequence variants: a joint consensus recommendation of the American College of medical genetics and genomics and the association for molecular pathology. Genet Med 2015;17:405-23.

21 Bertini E, Burghes A, Bushby K, et al. 134th ENMC International workshop: outcome measures and treatment of spinal muscular atrophy, 11-13 February 2005, Naarden, the Netherlands. Neuromuscul Disord 2005;15:802-16.

22 Annoussamy M, Lilien C, Gidaro T, et al. X-Linked myotubular myopathy: a prospective international natural history study. Neurology 2019;92:e1852-67.

23 Gibson B. Long-term ventilation for patients with Duchenne muscular dystrophy : physicians' beliefs and practices. Chest 2001;119:940-6.

24 Hardart MKM, Burns JP, Truog RD. Respiratory support in spinal muscular atrophy type I: a survey of physician practices and attitudes. Pediatrics 2002;110:e24.

25 Kinali M, Manzur AY, Mercuri E, et al. UK physicians' attitudes and practices in long-term non-invasive ventilation of Duchenne muscular dystrophy. Pediatr Rehabil 2006:9:351-64.

26 Ramelli GP, Hammer J. Swiss physicians' practices of long-term mechanical ventilatory support of patients with Duchenne muscular dystrophy. Swiss Med Wkly 2005;135:599-604

27 Bach JR, Chiou M, Saporito LR, et al. Evidence-Based medicine analysis of mechanical Insufflation-Exsufflation devices. Respir Care 2017;62:643.1-643.

28 Bach JR, Martinez D. Duchenne muscular dystrophy: continuous noninvasive ventilatory support prolongs survival. Respir Care 2011;56:744-50.

29 Bach JR, Niranjan V, Weaver B. Spinal muscular atrophy type 1: a noninvasive respiratory management approach. Chest 2000;117:1100-5.

30 Lewis CW, Carron JD, Perkins JA, et al. Tracheotomy in pediatric patients: a national perspective. Arch Otolaryngol Head Neck Surg 2003;129:523-9.

31 Berry JG, Graham DA, Graham RJ, et al. Predictors of clinical outcomes and hospital resource use of children after tracheotomy. Pediatrics 2009;124:563-72.

32 Berry JG, Graham RJ, Roberson DW, et al. Patient characteristics associated with inhospital mortality in children following tracheotomy. Arch Dis Child 2010;95:703-10.

33 Sterni LM, Collaco JM, Baker CD, et al. An official American thoracic Society clinical practice guideline: pediatric chronic home invasive ventilation. Am J Respir Crit Care Med 2016;193:e16-35.

34 Amin R, MacLusky I, Zielinski D, et al. Pediatric home mechanical ventilation: a Canadian thoracic Society clinical practice guideline executive summary. Canadian Journal of Respiratory, Critical Care, and Sleep Medicine 2017;1:7-36. 


\section{Original research}

35 Buj-Bello A, Fougerousse F, Schwab Y, et al. Aav-Mediated intramuscular delivery of myotubularin corrects the myotubular myopathy phenotype in targeted murine muscle and suggests a function in plasma membrane homeostasis. Hum Mol Genet 2008;17:2132-43.

36 Mack DL, Poulard K, Goddard MA, et al. Systemic AAV8-mediated gene therapy drives whole-body correction of myotubular myopathy in dogs. Mol Ther 2017;25:839-54.

37 Lawlor MW, Armstrong D, Viola MG, et al. Enzyme replacement therapy rescues weakness and improves muscle pathology in mice with X-linked myotubular myopathy. Hum Mol Genet 2013;22:1525-38.
38 Cowling BS, Chevremont T, Prokic I, et al. Reducing dynamin 2 expression rescues X-linked centronuclear myopathy. J Clin Invest 2014;124:1350-63.

39 Tasfaout H, Buono S, Guo S, et al. Antisense oligonucleotide-mediated Dnm2 knockdown prevents and reverts myotubular myopathy in mice. Nat Commun 2017:8:15661.

40 Sabha N, Volpatti JR, Gonorazky H, et al. PIK3C2B inhibition improves function and prolongs survival in myotubular myopathy animal models. $J$ Clin Invest 2016;126:3613-25.

41 Shieh PB, Kuntz N, Smith B, et al. ASPIRO phase 1/2 gene therapy trial in X-linked myotubular myopathy (XLMTM): update on preliminary safety and efficacy findings. Mol Ther 2019;27. 